\title{
ANALYSIS OF STRAIN STATE AND CRACKING OF COCNRETE SLEEPERS
}

\author{
Aidas JOKŪBAITIS, Juozas VALIVONIS, Gediminas MARČIUKAITIS \\ Department of Reinforced Concrete and Masonry Structures, Faculty of Civil Engineering, \\ Vilnius Gediminas Technical University, Saulettekio al. 11, 10223, Vilnius, Lithuania
}

Received 23 Oct 2015; accepted 08 Jan 2016

\begin{abstract}
Prestressed concrete sleepers are the most common type of the sleepers used on the railroad. They serve as rail supports and absorb loads induced by trains. Sleepers are important for the durability and safety of the railroad and are exposed to various loads and an agressive environment during exploitation. Therefore, different types of appearing damage can determine their reliability. The article briefly discusses possible causes of damage and the deterioration of prestressed concrete sleepers. End cracking and damage at the rail seat was determined during the inspection of used sleepers. Therefore, the strain state and cracking of the rail seat of the sleeper was analysed under static and dynamic loads. The paper provides the obtained results of experimental research of used and new sleepers.
\end{abstract}

Keywords: sleeper, dynamic load, static load, cracking, strain state.

\section{Introduction}

Concrete sleepers are a part of the layered railroad track structure consisting of rails that transfer train loads through an elastic pad to the sleeper that distributes it further to ballast and subgrade (TCRP Report 155 2012). Sleepers are the most affected part of the railroad structure. They absorb different type, direction and magnitude loads induced by trains and also are affected by reactions caused by the ballast underneath the sleeper.

The characteristics of sleepers have been constantly improved due to the development of new technologies and railroads used by higher speed trains. However, nowadays, damaged or deteriorated concrete sleepers appear on railroad tracks even before the end of their service life (Thun 2006; Remennikov, Kaewunruen 2014). Every year, $2-5 \%$ of concrete sleepers need the replacement or renewal of worn elements (Palomo et al. 2007). The replacement of damaged sleepers is an expensive and time consuming process. Therefore, it is important to determine the type and intensity of damages to sleepers and decide whether such sleeper is suitable for further exploitation.

There are different causes inducing the damage and deterioration of different parts of prestressed concrete sleepers (Gonzalez-Nicieza et al. 2008; Taherinezhad et al. 2013; Zeman et al. 2009; Ferdous, Manalo 2014; Csengen et al. 2015). The survey of North America and international organizations and professionals in many different positions within the railroad industry was performed and the major problems of concrete sleepers were determined (Dyk et al. 2012). The main causes of sleeper deterioration may vary depending on a country. However, the wear of fastening systems, tamping damage and cracking from dynamic loads are the most common causes of failure in prestressed concrete sleepers worldwide (Fig. 1).

Different causes of sleeper deterioration appears due to different stress state during its service life. The stress state of sleepers constantly varies at the stages of manufacturing and service. Initial stresses are induced in concrete at the stage of manufacturing sleepers due to technological factors. The release of pretensioned reinforcement induces initial stresses in the sleeper, which

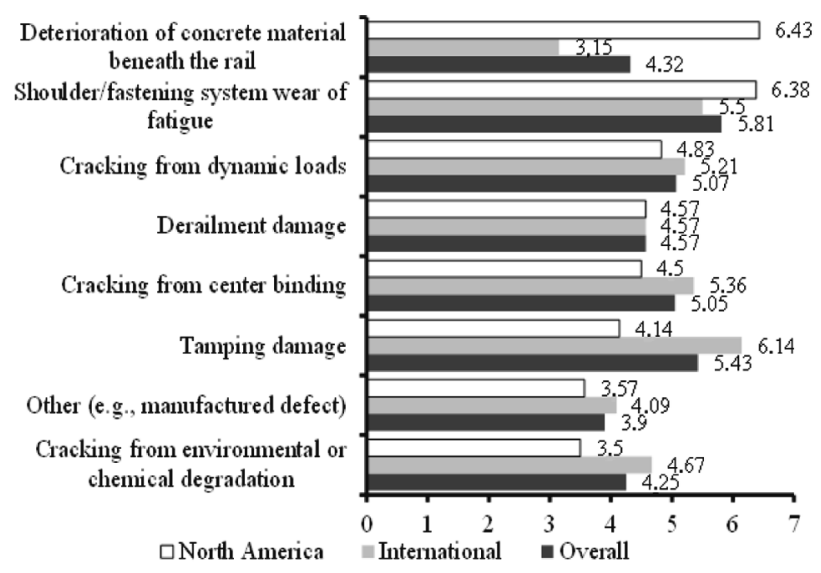

Fig. 1. Main failure causes of concrete sleeper (Dyk et al. 2012) 
is important for the behaviour of the anchorage zone (Jokūbaitis et al. 2014). Therefore, longitudinal cracks can appear in the sleeper due to pressure around the bolt hole induced by pretensioned reinforcement (Hasheminezhad 2015; Rezaie et al. 2012). The quality of the sleeper depends on concrete permeability (Bustos et al. 2015) composition of concrete, consolidation, the curing regime (temperature, duration and humidity), the method of release of prestressed reinforcement, prestressing force and concrete strength during release. It is impossible to avoid concrete micro-cracking during manufacturing prestressed concrete sleepers. However, an important point is ensuring proper technological stages during manufacturing such sleepers to minimize initial damages.

Initial stresses may not cause significant damage to the sleeper at the stage of manufacturing. However, the development of initial stresses can be accelerated during the service stage due to the acting different impacts, and therefore induce concrete cracking. Cyclic loads constantly affect prestressed concrete sleepers and can cause concrete fatigue, which results in concrete cracking and reduction in stiffness of the sleeper (Sykorova et al. 2011).

The durability of the sleeper also depends on environmental conditions during service. They are affected by various atmospheric impacts such as rain water, sun, the freezing and thawing of water, variation in temperature, various chemical compounds in soil and air and can damage concrete structure and reinforcement as well as accelerate sleeper deterioration. One or several of the introduced environmental impacts can cause delayed ettringite formation (DEF) (Collepardi 1999; Sahu, Thaulow 2004; Pawluk 2014), alkali aggregate reaction (AAR) (Shayan, Quick 1992), alcali silica reaction (ASR) (Quinhua, Weiqing 1997), reinforcement corrosion (Mohammadzadeh, Vahabi 2011) and concrete cracking due to freezing and thawing of water ( $\mathrm{Zi}$ et al. 2012). All of these effects have a negative impact on sleeper durability. AAR and ASR appear because of reactive aggregates (coarse, fine) in concrete, and alkali induced expansion occurs (Owsiak 2007), which causes concrete micro-cracking during heat treatment. The recrystalization of primary ettringite in concrete micro-cracks and pores during service is called delayed ettringite formation (DEF), which is expansive needle shape crystal forming due to internal sulphate attack (ISA). Alkali reaction accelerates the formation of delayed ettringite due to ISA. The freezing and thawing of water in concrete micro-cracks cause the further deterioration of concrete structure due to water expansion and hydraulic pressure at the tip of the crack. Unprotected reinforcement in the sleeper is affected by atmospheric impacts (water, chemical compounds). In time, the corrosion of reinforcement strarts and expansive corrosion products damage concrete structure and the bond between concrete and reinforcement. Additional stresses induced by corrosion products eventually can lead to the failure of the sleeper.
It is difficult to determine one effect causing the deterioration or failure of the sleeper due to various impacts affecting the sleeper at the stages of manufacturing and service. The initial damage to the concrete sleeper is caused by technological effects and increases during the exploitation of sleepers in the natural environment. Concrete structure and interface between reinforcement and concrete can be damaged due to the summation of stresses induced in concrete by different impacts, and sleeper deterioration can start after reaching a certain level of cracking. One impact can be the beginning of the other and, therefore the deterioration or failure of the prestressed concrete sleeper should be analyzed as a consequence of several impacts during manufacturing and service life of the structure.

The main object of this article is to analyse cracking and the strain state of prestressed concrete sleepers as well as to determine whether the stiffness and durability of the used sleeper is sufficient comparing with the new ones.

\section{Theoretical calculations}

An important point in the serviceability limit state is to control the cracking of the prestressed concrete element. Therefore, the theoretical cracking moment and crack width were calculated and compared to the experimental results of the static test. The theoretical calculation of the cracking moment was performed according to EN 1992-1-1 (2004). Assuming that stresses in the crosssection in the centre of the rail seat of the prestressed concrete sleeper take place due to prestress force $\left(P_{p}\right)$ and the eccentricity of prestress force $(e)$, and external loads are equal to the tensile strength of concrete $\left(f_{c t m}\right)$, and the cracking moment can be calculated according to Eqn (1):

$$
-\frac{P_{p}}{A_{c}}-\frac{P_{p} \cdot e \cdot y_{c}}{I_{c}}+\frac{M_{c r} \cdot y_{c}}{I_{c}}=f_{c t m},
$$

where: $\quad$ - prestress force after all losses; , , - area, moment of inertia and distance from the bottom of cross-section to the center of gravity, respectively.

The average crack spacing is assessed calculating crack width according to EN 1992-1-1 (2004) and the length over which slip between concrete and steel occurs assessed according to Model Code 1990 (CEB 1993). Experimental tests have demonstrated that one crack appeared and propogated up to the failure in the rail seat section of the sleeper. Thus, according to Model Code 1990 (CEB 1993), calculation was performed and crack width.was calculated as follows:

$$
w_{k}=l_{p, \max } \cdot\left(\varepsilon_{p m}-\varepsilon_{c m}-\varepsilon_{c s}\right),
$$

where: $\varepsilon_{p m}$ - average reinforcement strain within segment length $l_{p, \max } ; \varepsilon_{c m}$-average concrete strain within segment length $l_{p, \max } ; \varepsilon_{c s}$ - strain of concrete due to shrinkage. 
The length in Eqn (2) for single crack formation can be defined as:

$$
l_{p, \max }=\frac{\Delta \sigma_{p} \cdot \varnothing_{p}}{2 \cdot \tau_{b k} \cdot\left(1+\alpha_{e} \cdot \rho_{p, e f}\right)},
$$

where $\Delta \sigma_{p}$ - the magnitude of the tensile stress in prestressed reinforcement at any load level in which the decompression load is taken as the reference point; $\tau_{b k}-$ mean bond strength; $\varnothing_{p}$ - nominal strand diameter; $\alpha_{e}$ - the ratio between $E_{p}$ (steel modulus of elasticity) and $E_{c}$ (concrete modulus of elasticity); $\rho_{p, e f}-$ effective reinforcement ratio, $A_{p} / A_{c, e f} ; A_{p}$ - area of prestressed reinforcement; $A_{c, e f}$ - effective area of the concrete in tension.

The relative mean strain in Eqn (2) can be expressed as:

$$
\varepsilon_{p m}-\varepsilon_{c m}=\frac{\Delta \sigma_{p}}{E_{p}}-\frac{\beta \cdot\left(\frac{f_{c t m}}{\rho_{p, e f}} \cdot\left(1+\alpha_{e} \cdot \rho_{p . e f}\right)\right)}{E_{p}},
$$

where $\beta$ - empirical coefficient to assess average strain within $l_{p, \max } ; f_{c t m}$ - mean concrete tensile strength.

As a result of shrinkage, the strain of concrete affects the prestress force of reinforcement and causes loss of prestress, which, due to the shrinkage of concrete, was assessed in association with other losses. According to the above mentioned reason, concrete strain, because of shrinkage, is assessed in calculating crack width and should not be taken into accout estimating relative mean strain in the crack.

The contribution of stress in strands at different heights was considered according to crack height, because prestressed strands were located over the height of the cross-section (Fig. 2a).

\section{Materials and specimens}

Experimental research on prestressed concrete monoblock sleepers was performed at Vilnius Gediminas Technical University. Two types of sleepers were investigated. The ones were new and stored in the warehouse for three years while the others were used in the railroad track for three years. Both sleepers were manufactured at the same time from regular concrete. Portland cement CEM I $52,5 \mathrm{R}$ was used as a binder and granite and sand were used as coarse and fine aggregates respectively. The composition of the concrete mixture is presented in Table 1.

Concrete cubes $(100 \times 100 \times 100 \mathrm{~mm})$ were cut out of new sleepers and concrete compressive strength was determined. Standard cubic $(150 \times 150 \times 150 \mathrm{~mm})$ compressive strength was $80.6 \mathrm{MPa}$ and it was considerably larger than concrete design strength (C50/60). Concrete tensile strength was $4.95 \mathrm{MPa}$ and concrete porosity by water absorption was $3.3 \%$.

Sleepers were reinforced with twelve pretensioned indented three wire strands with $6.9 \mathrm{~mm}$ nominal diameter (Fig. 2a). Tensile strength of the strand $f_{p k}=1935 \mathrm{MPa}$
Table 1. Composition of concrete mixture

\begin{tabular}{l|l|c}
\hline \multicolumn{2}{c|}{ Material name, grade, fraction } & $\begin{array}{c}\text { Dry matter content } \\
\mathrm{kg} / 1 \mathrm{~m}^{3} \text { in concrete }\end{array}$ \\
\hline \multirow{2}{*}{ Cement } & $\begin{array}{l}\text { Portland cement CEM I } \\
52,5 \mathrm{R}\end{array}$ & 380 \\
\hline $\begin{array}{l}\text { Fine } \\
\text { aggregate }\end{array}$ & Sand fr. 0-4 & 773 \\
\hline $\begin{array}{l}\text { Coarse } \\
\text { aggregate }\end{array}$ & Granite fr. 5-8 & 406 \\
\cline { 2 - 3 } & Granite fr. 11-16 & 754 \\
\hline \multirow{2}{*}{ Additives } & Accelerating admixture & $0.5 \%$ \\
\cline { 2 - 3 } & Air entrainer & $0.57 \%$ \\
\hline Water & & 140 \\
\hline Water-cement ratio W/C & 0.37 \\
\hline Density of the concrete & 2453 \\
\hline
\end{tabular}

(design $1860 \mathrm{MPa}$ ), yield strength at $0.1 \%$ elongation $f_{p 0.1 k}=1677 \mathrm{MPa}$ (design $1690 \mathrm{MPa}$ ) and modulus of elasticity $E_{p}=200.7 \mathrm{GPa}$.

Sleepers were inspected before testing. There was no major cracking observed in new sleepers (Fig. 2b) except for micro-cracks on the surface of concrete. It formed during the manufacturing stage due to concrete shrinkage. The used sleepers had a crack beneath the rail seat propagating from the bottom of the sleeper towards the rail seat (Fig. 2c). Crack widths of the sleeper cross-section

a)

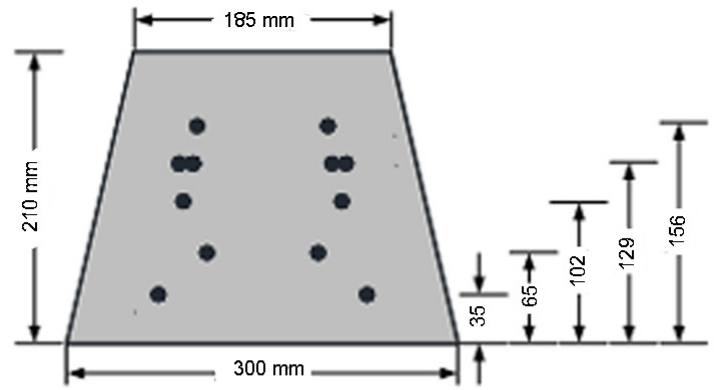

b)

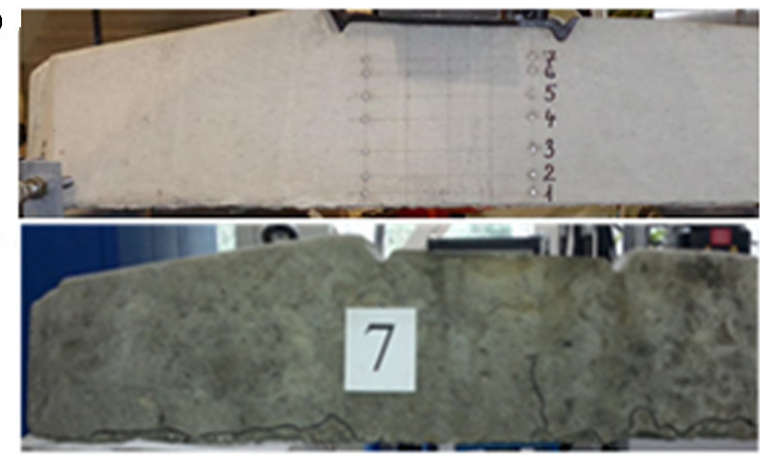

d)

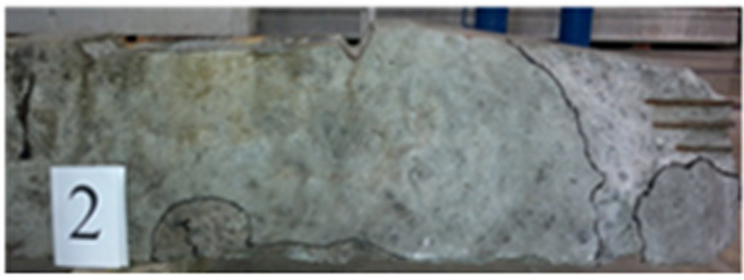

Fig. 2. Prestressed concrete sleepers: a) cross-section; b) new sleeper; c), d) used sleeper 
were $0.02-0.06 \mathrm{~mm}$ at the bottom and $0.005-0.03 \mathrm{~mm}-$ $15 \mathrm{~mm}$ from the bottom. Crack height reached about a half of sleeper height at the rail seat section. Some of used sleepers had cracks at the end of the sleeper, spalled peaces of concrete and uncovered reinforcement (Fig. 2d). No major cracking was observed in the middle of new and used sleepers. Therefore, the rail seat section of the sleeper was the object of the experimental research.

\section{Test setup}

New and used sleepers were tested under static and dynamic loads at the rail seat section. The tests were performed according to EN 13230-1 (2009a, 2009b) (Fig. 3). The programme of experimental research is presented in Table 2.

Table 2. Programme of experimental research

\begin{tabular}{ccc}
\hline Test type & New sleepers & Used sleepers \\
\hline Static test at the rail seat & 2 & 5 \\
\hline Dynamic test at the rail seat & 3 & 5 \\
\hline
\end{tabular}

A static load test was performed according to the graph shown in Figure 3a. The sleeper was loaded until concrete tensile strength was reached and the first crack appeared. After the cracking load was reached, the sleeper was unloaded and residual crack width was measured. Further loading of the sleeper was performed in steps increasing the load by $10 \mathrm{kN}$, and residual crack width was controlled following every step of the load.

A dynamic load test was performed according to the graph presented in Figure 3b. The sleeper was loaded under a static load until the designed cracking load followed by a dynamic load. The frequency of the load was $5 \mathrm{~Hz}$. Every 5000 cycles, the load was increased by $20 \mathrm{kN}$, and loading amplitude was increasing until failure occured. Following every cycle of loading, the sleeper was unloaded and residual crack width was measured.

According to EN 13230-1 (2009a, 2009b), three reference load levels should be satisfied for the sleeper to pass the test: 1. reference loading level at which concrete tensile strength is reached and the first crack appears (cracking load $-F_{c r}$ ); 2 . reference loading level that causes a residual crack of $0.05 \mathrm{~mm}\left(F_{0.05}\right) ; 3$. reference loading level that causes a residual crack of $0.5 \mathrm{~mm}\left(F_{0.5}\right)$ or failure load.

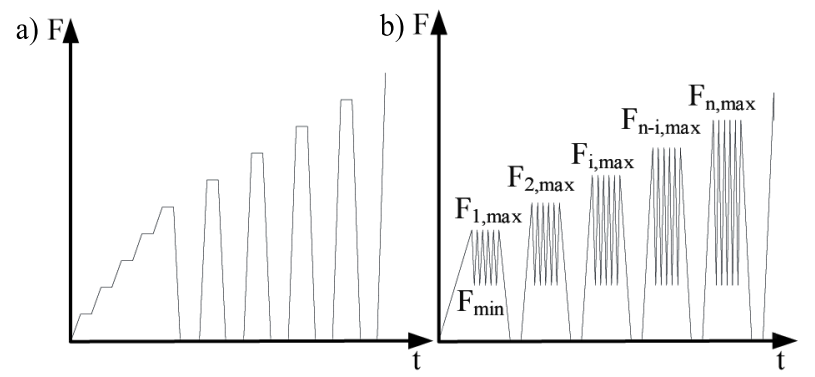

Fig. 3. Experimental test process: a) under static load; b) under dynamic load

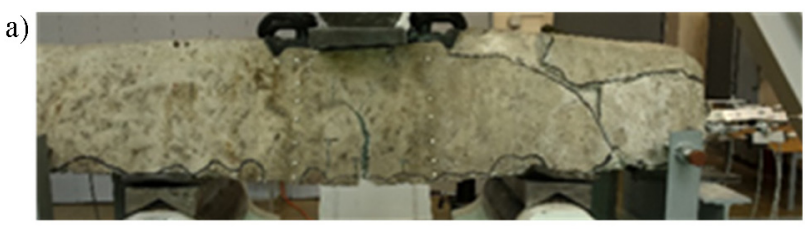

b)

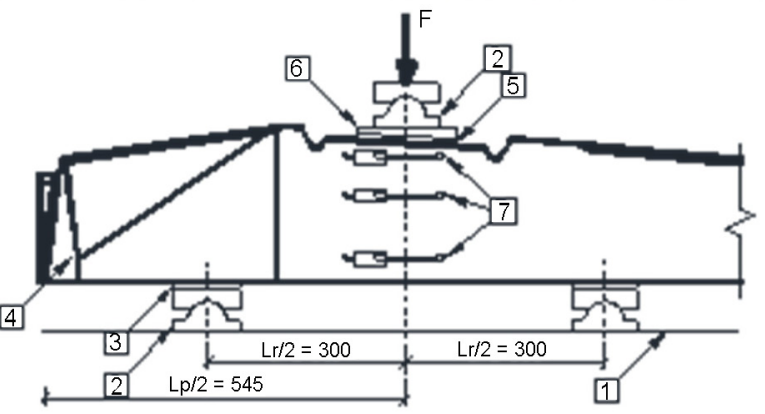

Fig. 4. Arrangement of strain measurement devices: a) testing view with DEMEC gauges; b) testing scheme with LVDT gauges. 1 - rigid support; 2 - hinge support; 3 - elastic pad; 4 - prestressed concrete monoblock sleeper; 5 - standard rail pad; 6 - inclined plate

Concrete strains, through the height of sleepers, were measured during the tests under the static and dynamic load. Three linear variable differential transformer (LVDT) gauges at one side of the sleeper were mounted at different levels of the rail seat section (Fig. 4b). On the other side of the sleeper, demountable mechanical strain gauges (DEMEC) were used for measuring concrete strain (Fig. 4a). Two types of concrete strain measurement devices were used for checking if obtained results coincided. Also, LVDT gauges occupy more space, and hence fewer points can be measured unlike in the case of DEMEC gauges.

At the end of the sleeper slip of the first row reinforcement in the tension zone of cross-section of the sleeper using two LVDT gauges mounted on each strand was measured. The accuracy of all used LVDT gauges was $0.001 \mathrm{~mm}$.

\section{Analysis of experimental results}

Cracking load and residual crack width were controllable variables during experimental tests on prestressed concrete sleepers. Residual crack width should not exceed $0.05 \mathrm{~mm}$ at the reference load $\left(F_{0.05}\right)$. The results of all cracking loads of concrete sleepers are presented in Tables 3 and 5 .

All reference loads (cracking load $F_{c r}=149.6 \mathrm{kN}$, load that causes residual crack width of $0.05 \mathrm{~mm} F_{0.05}=$ $269.3 \mathrm{kN}$ ) were satisfied according to experimental results (Table 3).

Experimental results showed that the crack widths of the used prestressed concrete sleeper were greater or almost equal to the crack width of new sleepers (Fig. 5a). The difference at the level of the maximum load was $2-11 \%$. As for new and used sleepers, load-crack width relationships were similar from $0.5 \mathrm{~mm}$ crack width up 
Table 3. Summary of static test results

\begin{tabular}{ccc}
\hline No. & $F_{c r}, \mathrm{kN}\left(M_{c r}, \mathrm{kNm}\right)$ & $F_{0.05}, \mathrm{kN}\left(M_{0.05}, \mathrm{kNm}\right)$ \\
\hline NS 330_1 & $190(25.2)$ & $320(42.4)$ \\
\hline NS 432_1 & $170(22.5)$ & $320(42.4)$ \\
\hline US 2_1 & - & $330(43.7)$ \\
\hline US 5_1 & - & $370(49.0)$ \\
\hline US 6_1 & - & $340(45.0)$ \\
\hline US 7_1 & - & $310(41.1)$ \\
\hline US 8_1 & - & $320(42.4)$ \\
\hline
\end{tabular}

Note: $\mathrm{N}$ - new sleeper; $\mathrm{U}-$ used sleeper; $\mathrm{S}-$ static load.

to the failure of specimens (Fig. 5a). Before, the crack widths of used sleeper increased faster due to the initial pre-cracking. Residual crack widths in used sleepers did not propagated at the levels of the lower load and strated increasing at a load of 190-280 kN (Fig. 5b), which means that during the exploitation of the railroad track, these loads could occur and induce the cracking of the rail seat section. The difference between residual crack widths at the levels of maximum load varied between 1.4-2.6 times (Fig. 5b). The scatter of the results can be influenced by the aggregates and pieces of the crushed concrete changing a position in the crack during loading and unloading specimens.

Theoretical and experimental results of crack width under a static load are presented in Table 4. Two sleepers were tested and variations of crack widths were up to $43 \%$ under the levels of the lower load (higher than the cracking load) decreasing up to $10 \%$ under a load of $0.6 F_{\max }$. The difference between theoretically calculated crack width and the experimental crack width of sleeper
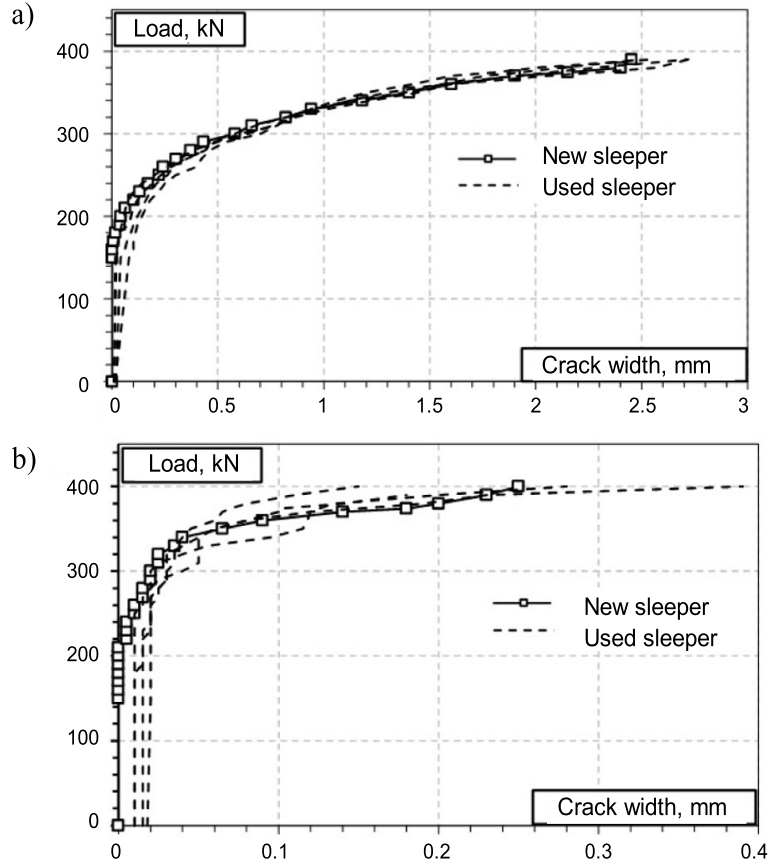

Fig. 5. Crack widths: a) under static load; b) residual crack width
NS330_1 was up to $8 \%$ while the crack width of sleeper NS432_ 1 was lower from 9\% at the level of the higher load up to $48 \%$ at the level of the lower load. Therefore, mean experimental crack width was lower up to $22 \%$ comparing with theoretically calculated crack width. The calculation of crack width in case of the appearance of one crack in the prestressed concrete sleeper, according to Model Code 1990 (CEB 1993), gives a good agreement with experimental results under load levels approximately equal to $0.6 F_{\max }$.

The theoretical calculation of the cracking moment of new sleepers gave a fairly good agreement with experimental results and the difference was $0-11 \%$. The cracking moment of used sleepers could not be determined due to the pre-cracking of the rail seat section before the test.

Table 4. Summary of crack width results

\begin{tabular}{lccccc}
\hline \multicolumn{1}{c}{$F, \mathrm{kN}$} & 200 & 210 & 220 & 230 & 240 \\
\hline$w_{330 \_1}$ & 0.086 & 0.124 & 0.152 & 0.19 & 0.23 \\
\hline$w_{432 \_1}$ & 0.06 & 0.09 & 0.12 & 0.16 & 0.21 \\
\hline$w_{\text {calc }}$ & 0.089 & 0.117 & 0.149 & 0.175 & 0.23 \\
\hline$w_{\text {calc }} / w_{330 \_1}$ & 1.03 & 0.94 & 0.98 & 0.92 & 1 \\
\hline$w_{\text {calc }} / w_{432 \_1}$ & 1.48 & 1.3 & 1.24 & 1.09 & 1.1 \\
\hline$w_{\text {calc }} / w_{\text {m,exp }}$ & 1.22 & 1.09 & 1.1 & 1 & 1.05 \\
\hline
\end{tabular}

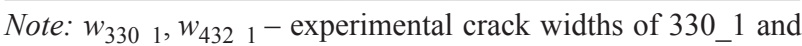
432_1 sleepers; $w_{\text {calc }}-$ theoretically calculated crack width; $w_{\text {m,exp }}-$ mean experimental crack width.

The distribution character of concrete tensile and compressive strains at the rail seat section of new and used sleepers is similar (Fig. 6). However, difference between tensile and compressive concrete strains of new and used sleepers is up to $17 \%$ and up to $24 \%$, respectively. The highest concrete compressive strains 0.00389 and 0.00342 were in used sleepers US6_1 and US7_1, respectively, and were influenced by the failure mode. These sleepers failed in the compression zone of the rail seat section due to concrete crushing. Other sleepers under the static load failed due to reinforcement rupture, and concrete compressive strains were of a lower magnitude.

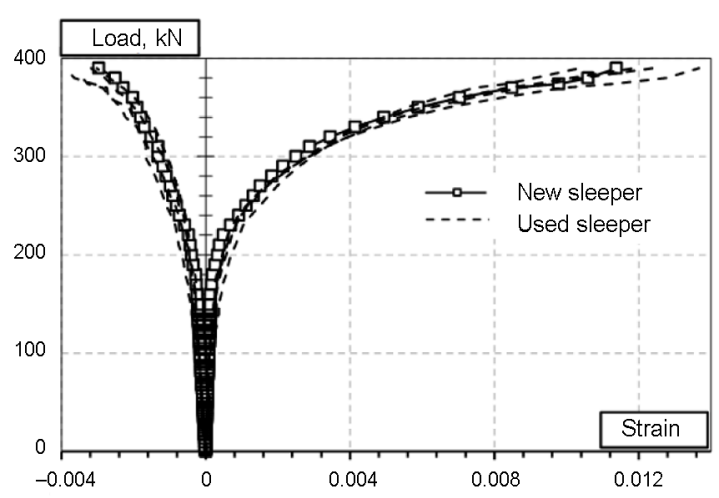

Fig. 6. Load-strain relationships under static load 
Table 5. Summary of dynamic test results

\begin{tabular}{ccc}
\hline No. & $F_{c r} . \mathrm{kN}\left(M_{c r} . \mathrm{kNm}\right)$ & $F_{0.05} . \mathrm{kN}\left(M_{0.05} . \mathrm{kNm}\right)$ \\
\hline ND 328_1 & $169.6(22.5)$ & $284.4(37.7)$ \\
\hline ND 330_2 & $169.6(22.5)$ & $284.4(37.7)$ \\
\hline ND 800_2 & $169.6(22.5)$ & $284.4(37.7)$ \\
\hline UD 2_2 & - & $244.4(32.4)$ \\
\hline UD 5_2 & - & $284.4(37.7)$ \\
\hline UD 6_2 & - & $264.4(35.0)$ \\
\hline UD 7_2 & - & $244.4(32.4)$ \\
\hline UD 8_2 & - & $284.4(37.7)$ \\
\hline
\end{tabular}

Note: $\mathrm{N}$ - new sleeper; $\mathrm{U}$ - used sleeper; $\mathrm{D}$ - dynamic load.

A dynamic test of prestressed concrete sleepers was performed under unidirectional cyclic loading (Fig. 4b). Concrete strains on the sides of the rail seat section of the sleeper and crack widths were measured in each step of the load every 5000 load cycles (from 0 up to 55000 cycles). The experimental results of the reference loads of new and used sleepers under the cyclic load are presented in Table 5.

All reference loads were satisfied and all experimental loads were higher than required (cracking load $F_{c r}=149.6 \mathrm{kN}$, load that causes a residual crack width of $0.05 \mathrm{~mm} F_{0,05}=224 \mathrm{kN}$ ). The dynamic load that caused a residual crack width of $0.05 \mathrm{~mm}$ in used sleepers was equal or up to $16 \%$ lower comparing with new sleepers (Table 5). This indicates that the initial damage of used sleepers influence the cracking of the sleeper and initiate a reduction of stiffness of the rail seat section. The dynamic load comparing with static one accelerates the propagation of residual crack width (Tables 3 and 5).

Figure 7 shows the dependence of crack width $(w)$ versus the number of load cycles $(N)$ at the rail seat section of new and used sleepers. The results of sleeper tests under the dynamic load showed that crack widths of used sleepers were higher comparing with those of new sleepers (Fig. 7a). The difference between crack widths appeared at the beginning of the test on the dynamic load due to the initial precracking of used sleepers. Cracks in used sleepers propagated more rapidly in the first couple of load steps up to 20,000 load cycles. However, difference between crack widths of new and used sleepers decreased between 25,000-35,000 load cycles and at some point in this region became equal. At higher load amplitudes from 40,000 load cycles, the degradation of the rail seat section of used sleepers was faster and crack widths propagated more rapidly up to the failure of specimens. The difference between crack widths of new and used sleepers before failure was $27-37 \%$. However, the variation of the results of residual crack widths after the dynamic load was larger (Fig. 7b). The difference between residual crack widths of the new and used sleeper was up to 2.7 times.

Load-crack width relationship (Fig. 7) corresponded to load-concrete tensile strain relationship (Fig. 8) at the a)
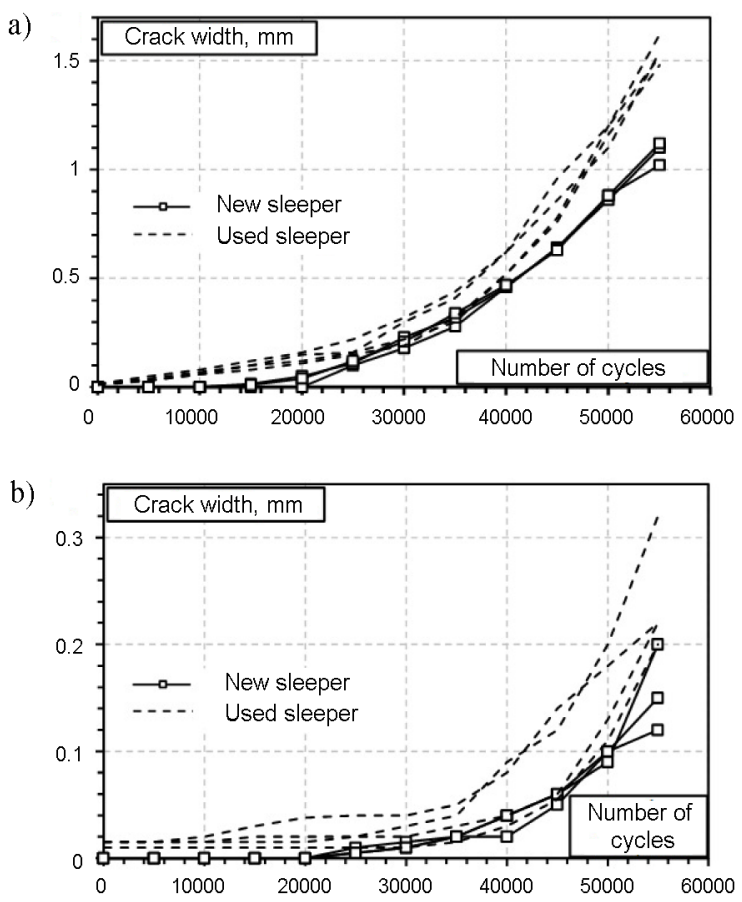

Fig. 7. $w$ - $N$ relationships: a) crack width under dynamic load; b) residual crack width

rail seat section of the new and used sleeper. Concrete tensile strain of used sleepers was significantly higher than that of new sleepers and difference varied from 1.5 up to 2 times. Concrete compressive strains in used sleepers were varying. The scatter of the results can be explained by the failure mode and a different level of damage of used sleepers. Sleeper UD6_2 failed due to the slippage of reinforcement followed by reinforcement rupture. Compared with new sleeper, it caused 1.8 times lower and 1.5 times higher concrete compressive and tensile strains, respectively. Concrete compressive strains in other used sleepers were approximately equal or 1.5 times higher than new sleepers. Concrete tensile strains propagated more rapidly in used sleepers than those in the new ones (Fig. 8). It was influenced by initial damages of used sleepers during exploitation on the railroad track, which caused residual strains in concrete.

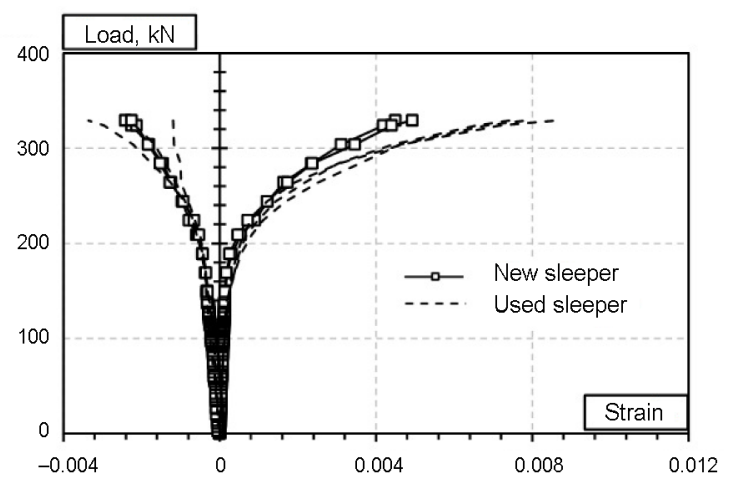

Fig. 8. Load-strain relationships under dynamic load 


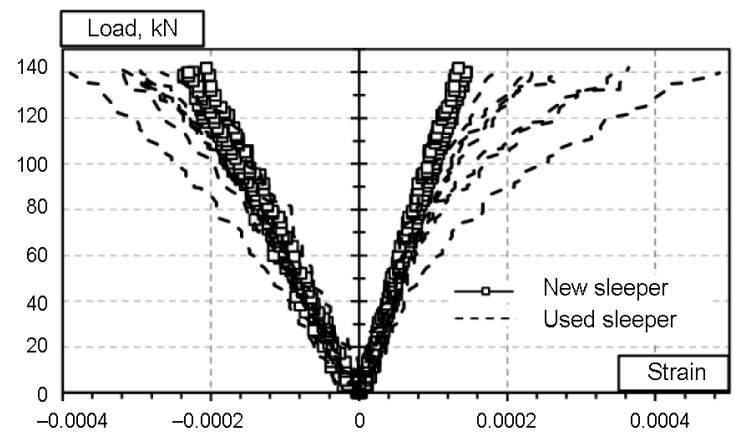

Fig. 9. Load-strain relationships of concrete at rail seat section

The initial damage of reinforcement anchorage zone of used sleepers had a negative influence on the deformation of the rail seat section before cracking loads were reached in new sleepers. Figure 9 describes concrete tensile and compressive strains at the rail seat section under the level of the lower load (lower than concrete cracking load). The distribution of concrete strains in new sleepers was approximately linear and concrete was at an elastic stage. On the contrary, the strains of used sleepers deviated from linear distribution and plastic deformations were developing. This was influenced by the initial damage and pre-cracking of used sleepers, which caused a higher degradation rate of concrete.

Comparing experimental results under static and dynamic loads concrete strains were analysed up to the selected level of the force $(330 \mathrm{kN})$ at which the last measurements were taken during the dynamic test (Fig. 10). Concrete compressive and tensile strains of new sleepers were approximately equal (Fig. 10a). In contrast, concrete tensile strains of used sleepers were higher under the dynamic load up to 2,3 times comparing with the results of the static test (Fig. 10b). This is conditioned by the initial pre-cracking of the sleeper during exploitation on the railroad track. The dynamic load had an additional negative impact on the degradation of the rail seat section. It caused stress concentration in the cracked zone of the concrete sleeper during cyclic loading. Due to bond failure in the crack, friction between concrete and reinforcement appears in the tension zone of the rail seat section and gradually weakens reinforcement during cyclic loading. Reinforcement was bending under a slightly higher angle at the edges of concrete in the crack. The lower is the stiffness of the sleeper the higher is the bending angle of reinforcement during cyclic loading. A part of reinforcement in the crack was degrading more than in other parts.

In some sleepers, the distribution of concrete strains in the cross-section of the rail seat was not linear (Fig. 10). Concrete tensile strains were higher in the protective layer of concrete. This effect can be explained by the influence of concrete cracking. The main crack was propagating and the tension zone of concrete was devided in blocks. When the main crack was propagating in height and width, secondary small cracks appeared in
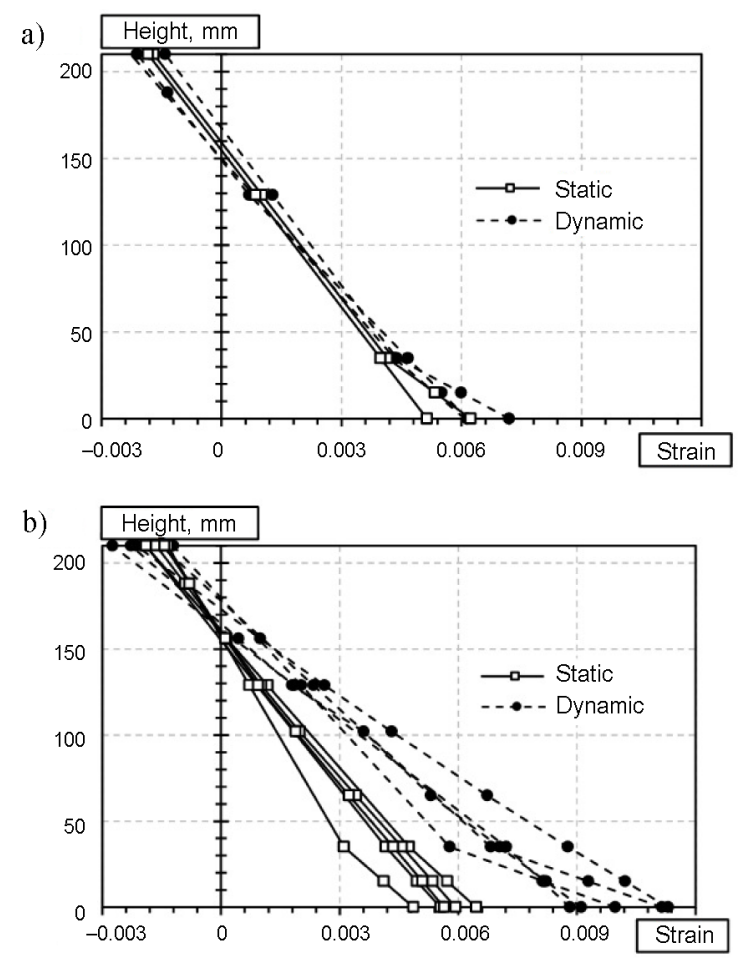

Fig. 10. Concrete strains at the cross-section of the rail seat: a) new sleepers; b) used sleepers

concrete blocks that did not reach the height of reinforcement. Additional cracks increased tensile strains in the protective layer of concrete and caused strain deviation from linear distribution.

Experimental results showed that a lower height of the concrete compression zone was found in used sleepers under the dynamic load (Fig. 10b). This means that cracking in the tension zone of the rail seat cross-section was propogating and the stiffness of the sleeper was decreasing more rapidly under the dynamic load. Therefore, dynamic loads are more dangerous than the static ones, which causes more damage to the sleeper.

\section{Conclusions}

Prestressed concrete sleepers are the most vulnerable part of the railroad track. Their behaviour is very complex due to severe environmental impacts and various mechanical loads that induce damage of concrete and the deterioration of the sleeper. This was confirmed by damages found in used sleepers during the observation and the results of experimental research of used and new sleepers.

The sleepers used on the railroad track for three years had a crack at the bottom of the rail seat section, and some of those had major cracking and concrete spalling off at the ends. Dynamic load caused damage of bond between concrete and pretensioned reinforcement and concrete plastic deformations at the compressive zone of rail seat section. Therefore, this influenced a higher rate of cracking and concrete strain development of used sleepers. 
The cracking moment calculated according to Eurocode 2 (EN 1992-1-1) methodology and determined with the help of the performed experiments has a fairly good agreement with the results of the experimental research. Theoretical calculations gave conservative results and it was up to $11 \%$ lower comparing with experimental values. The results showed that this methodology is appropriate for calculation of cracking moment of prestressed concrete sleepers.

The results of crack width calculated according to Model Code 1990 (CEB 1993) methodology and determined with the help of the performed experiments differ up to 22\%. However, according to Model Code 1990 (CEB 1993), the calculation of crack width in case of the appearance of one crack in the prestressed concrete sleeper gives a fairly good agreement with experimental results under the levels of the load approximately equal to $0.6 F_{\max }$. The difference between the results of theoretical and experimental crack width at such a load level was $10 \%$. The results showed that this methodology is appropriate for calculation of crack width of prestressed concrete sleepers under static load.

Concrete strains and the cracking of the sleeper propagated more rapidly under the influence of the dynamic load, which indicates this load is more dangerous than the static one for the reduction of stiffness of the sleeper.

Reference cracking loads of new and used sleepers were satisfied according to EN 13230-1 (2009a, 2009b). Despite that, crack widths and concrete tensile strains in the rail seat section were higher in used sleepers than those in the new ones and made up to $38 \%$ and $46 \%$, respectively. This indicates that the pre-cracking of used sleepers and the influence of the dynamic load have an impact on a higher degradation rate of the rail seat section of prestressed concrete. Therefore, a reduction in the stiffness of used sleepers has a negative impact on durability.

\section{Acknowledgements}

Authors are grateful to Civil Engineering Scientific Research Centre of Vilnius Gediminas Technical University for equipment and infrastructure, which were employed for investigation.

\section{References}

Bustos, F.; Martinez, P.; Videla, C.; Lopez, M. 2015. Reducing concrete permeability by using natural pozzolans and reduced aggregate-to-pasteratio, Journal of Civil Engineering and Management 21(2): 165-176. http://dx.doi.org/10.3846/13923730.2013.802719

Comite Euro-International du Beton (CEB). 1993. CEB-FIP Model Code 1990. Bullettin d'Information, No. 203-205. Thomas Telford, London.

Csengen, M. V.; Wolf, H. E.; Dersch, M. S.; Edwards, J. R. 2015. Exploration of alernatives for prestressed concrete monoblock crosstie design based on flexural capacity, in JRC2015 Conference Proceedings, 23-26 March 2015, San Jose, CA, USA, 1-6.
Collepardi, M. 1999. Damage by delayed ettringite formation, Concrete International 21(1): 69-74.

Dyk, B. J. V.; Dersch, M. S.; Edwards, J. R. 2012. International concrete crosstie and fastening system survey - final results. Technical report, RailTEC, UIUC, USA. 38 p.

EN 13230-1 Railway applications. Track. Concrete sleepers and bearers. Part 1: General requirements. Brussels, 2009a.

EN 13230-1 Railway applications. Track. Concrete sleepers and bearers. Part 2: Prestressed monoblock sleepers. Brussels, 2009b.

EN 1992-1-1 Eurocode 2. Design of concrete structures. Part 1-1: General rules and rules for buildings. Brussels, 2004.

Ferdous, W.; Manalo, A. 2014. Failures of mainline railway sleepers and suggested remedies - review of current practice, Engineering Failure Analysis 44: 17-35.

http://dx.doi.org/10.1016/j.engfailanal.2014.04.020

Gonzalez-Nicieza, C.; Alvarez-Fernandez, M. I.; Menendez-Diaz, A.; Alvarez-Vigil, A. E.; Ariznavarreta-Fernandez, F. 2008. Failure analysis of concrete sleepers in heavy haul raiway tracks, Engineering Failure Analysis 15: 90-117. http://dx.doi.org/10.1016/j.engfailanal.2006.11.021

Hasheminezhad, A. 2015. Analytical study on longitudinal crack control for B70 mono-block pre-stressed concrete sleeper, Engineering Failure Analysis 49: 1-10. http://dx.doi.org/10.1016/j.engfailanal.2014.12.005

Jokūbaitis, A.; Valivonis, J.; Zubrus, A. 2014. The influence of prestress losses on the anchorage zone of prestressed concrete member, Engineering Structures and Technologies 6(1): 25-32. http://dx.doi.org/10.3846/2029882X.2014.957902

Mohammadzadeh, S.; Vahabi, E. 2011. Time-dependent analysis of B70 pre-stressed concrete sleeper subject to deterioration, Engineering Failure Analysis 18: 421-432. http://dx.doi.org/10.1016/j.engfailanal.2010.09.030

Owsiak, Z. 2007. Testing alkali-reactivity of selected concrete aggregates, Journal of Civil Engineering and Management 13(3): 201-207.

Palomo, A.; Jimenez, A. F.; Hombrados, C. L.; Lleyda, J. L. 2007. Railway sleepers made of alkali activated fly ash concrete, Revista Ingenieria de Construccion 22(2): 7580. http://dx.doi.org/10.4067/s0718-50732007000200001

Pawluk, J. 2014. Corrosion hazards of railway sleepers, part I, Cement Wapno Beton R.18/80(3): 174-184.

Quinhua, J.; Weiqing, L. 1997. Investigations on concrete railway ties suffering from alkali-silica reaction, Cement and Concrete Research 27(1): 107-113.

http://dx.doi.org/10.1016/S0008-8846(96)00186-X

Remennikov, A. M.; Kaewunruen, S. 2014. Experimental load rating of aged railway concrete sleepers, Engineering Structures 76: 147-162. http://dx.doi.org/10.1016/j.engstruct.2014.06.032

Rezaie, F.; Shiri, M. R.; Farnam, S. M. 2012. Experimental and numerical studies of longitudinal crack control for prestressed concrete sleepers, Engineering Failure Analysis 26: 21-30.

http://dx.doi.org/10.1016/j.engfailanal.2012.07.001

Sahu, S.; Thaulow, N. 2004. Delayed ettringite formation in Swedish concrete railroad ties, Cement and Concrete Research 34(9): 1675-1681.

http://dx.doi.org/10.1016/j.cemconres.2004.01.027

Shayan, A.; Quick, G. W. 1992. Microscopic features of cracked and uncracked concrete railway sleepers, ACI Materials Journal 89(4): 348-361.

Sykorova, J.; Bartova, J.; Štemberk, P. 2011. Analysis of prestressed concrete sleeper under extreme loading conditions, in Proceedings of the $16^{\text {th }}$ International Conference "Mechanika", 7-8 April 2011, Kaunas, Lithuania, $282-286$. 
Taherinezhad, J.; Sofi, M.; Mendis, P. A.; Ngo, T. 2013. A review of behaviour of prestressed concrete sleepers, Electronic Journal of Structural Engineering 13(1): 1-16.

TCRP Report 155. 2012. Track design handbook for light rail transit. $2^{\text {nd }}$ ed. Transportation research board, Washington, D.C.

Thun, H. 2006. Assesment of fatigue resistance and strength in existing concrete structures: Doctoral thesis. Luela University of Technology, Sweden. $173 \mathrm{p}$.
Zeman, J. C.; Edwards, J. R.; Barkan, C. P. L.; Lange, D. A. 2009. Failure mode and effect analysis of concrete ties in North America, in Proceedings of the $9^{\text {th }}$ International Heavy Haul Conference, 22-25 June 2015, Shanghai, China, 270-277.

Zi, G.; Moon, D. Y.; Lee, S. J.; Jang, S. Y.; Yang, S. C.; Kim, S. S. 2012. Investigation of a concrete railway sleeper failed by ice expansion, Engineering Failure Analysis 26: 151-163. http://dx.doi.org/10.1016/j.engfailanal.2012.07.023

Aidas JOKŪBAITIS. PhD student at the Department of Reinforced Concrete and Masonry Structures, Vilnius Gediminas Technical University (VGTU). Research interests: mechanics of reinforced and prestressed concrete structures.

Juozas VALIVONIS. Prof., Dr at the Department of Reinforced Concrete and Masonry Structures, Vilnius Gediminas Technical University (VGTU). Publications: the author and co-author of more than 92 scientific publications, 4 textbooks, 12 course books. Research interests: theory of reinforced concrete behaviour, composite structures, reinforced concrete bridges.

Gediminas MARČIUKAITIS. Prof., Dr Habil at the Department of Reinforced Concrete and Masonry Structures, Vilnius Gediminas Technical University (VGTU). PhD from Kaunas Politechnical Institute in 1963. Research visit to the University of Illinois (1969). A Habilitated Doctor from Moscow Civil Engineering University in 1980. Professor (1982). The author and co-author of 5 monographs, 8 textbooks, 5 coursebooks and more than 300 scientific articles. Research interests: mechanics of reinforced concrete, masonry and layered structures, new composite materials, investigation and renovation of buildings. 